\title{
Proper Mg0 Addition in Blast Furnace Operation
}

\author{
Fengman SHEN, ${ }^{1)}$ Xin JIANG, ${ }^{1)}$ Gangsheng WU, ${ }^{1,2)}$ Guo WEI, ${ }^{1)}$ Xiaogang $\mathrm{LI}^{21}$ and Yansong SHEN ${ }^{31}$ \\ 1) Northeastern University, Shenyang 110004, China. \\ 2) Baotou Iron and Steel (Group) Co., Ltd., Baotou 014010, China. \\ 3) School of Materials Science \& Engineering, University of New South Wales, Sydney 2052, Australia.
}

(Received on July 13, 2005; accepted on October 19, 2005)

\begin{abstract}
Based on laboratory experiment, the effects of $\mathrm{MgO}$ on sintering process and metallurgical properties of sintered ore are examined. The experiment results show that, adding no or small amount of $\mathrm{MgO}$ in sintering, the sintering productivity can be improved, and the sintered ore can have high cold strength and small temperature range of cohesive zone and as a result the permeability of cohesive zone can be improved and the total pressure drop of blast furnace (BF) can be decreased. In this paper a new process of proper $\mathrm{MgO}$ addition into BF operation is proposed and in this process $\mathrm{MgO}$ content in BF slag can meet the requirement and at the same time RDI of sintered ore is low.
\end{abstract}

KEY WORDS: MgO; sintered ore; blast furnace; cohesive zone.

\section{Introduction}

As the grade of $\mathrm{BF}$ charge is increasingly improved, the relative content of $\mathrm{Al}_{2} \mathrm{O}_{3}$ in slag is increased and as a result the slag fluidity and desulphurization ability are decreased. In order to solve this problem, the common solution is to add dolomite etc. into sintering raw materials, to increase $\mathrm{MgO}$ content and then improve the fluidity and desulphurization ability of slag. The effect of $\mathrm{MgO}$ on sintering process and on sintered ore (strength, RDI and softening/melting behaviour at high temperature) has been reported widely. ${ }^{1-9)}$ However, the previous reports did not examine the effect of $\mathrm{MgO}$ on the whole sintering-BF process systematically. In this paper, based on laboratory experimental study, the positive and negative effects of $\mathrm{MgO}$ on sintering process and metallurgical properties of sintered ore are examined and a new process of appropriate $\mathrm{MgO}$ addition into BF is proposed.

\section{Effect of MgO on Sintering Process}

\subsection{Sintering Experiment}

Under laboratory condition, various iron concentrates are used as raw materials to examine the effect of $\mathrm{MgO}$ content on sintering process under two basicity conditions ( $R=\% \mathrm{CaO} / \% \mathrm{SiO}_{2}=1.36$ and $\left.R=1.76\right)$, by using the $\Phi 150 \mathrm{~mm}$ sintering test system. In the experiment, $\mathrm{MgO}$ is added in the form of dolomite. The $\mathrm{MgO}$ content in sintered ore are $1.3 \%, 1.7 \%, 2.1 \%, 2.5 \%$ and $3.0 \%$ respectively. The chemical compositions of the sinter raw materials are listed in Table $\mathbf{1}$ and other sintering test conditions are listed in Table 2.

\subsection{Results and Discussion}

(1) Effect on Sintering Productivity: Figure 1 shows the effect of $\mathrm{MgO}$ content on productivity of sintering. It can be seen in the figure that, as $\mathrm{MgO}$ content increases, the productivity of sintering shows a decreasing trend. This is because that, during the sintering process, the decomposition and mineralization of dolomite will consume heat. Under the same chemical composition of raw material and flux and the same experimental condition, heat consumption will control the sintering productivity. Therefore, under the experimental condition, more $\mathrm{MgO}$ will need more heat consumption and then the productivity of sintering will be decreased.

(2) Effect on Strength of Sintered Ore: Figure 2 shows the effect of $\mathrm{MgO}$ content on Drum Index (DI) of sintered ore. It shows that, when $R=1.36, \mathrm{MgO}$ content does not have significant effect on the strength of sintered ore; whereas when $R=1.76$, the DI of sintered ore is decreased as $\mathrm{MgO}$ content increases. This is because, under low basicity $(R=1.36)$ the glass phase acts as the dominant binding phase. $\mathrm{MgO}$ does not have much effect on glass phase, whereas under higher basicity, it is difficult for $\mathrm{MgO}$ in raw materials to form binding phase of low-melting point and at the same time the generation of calcium ferrite will decrease. Therefore the DI of sintered ore is decreased as $\mathrm{MgO}$ content increases.

(3) Effect on Other Sintering Index: According to industrial practice experience, dolomite does not have strong stickiness, therefore excessive addition of dolomite will affect pelletization performance. In addition, as dolomite content increases, unit energy consumption in sintering process will be increased. This is because that, carbonate decomposition is an endothermic reaction. When more dolomite is added into the sintered raw materials, much more energy will be required to meet endothermic reaction of carbonate decomposition. Therefore, more $\mathrm{MgO}$ addition in sintering will be not favorble to unit energy consumption 
Table 1. Chemical composition of sinter raw materials.

\begin{tabular}{cccccc}
\hline Test & $\mathrm{TFe}(\mathrm{wt} \%)$ & $\mathrm{MgO}(\mathrm{wt} \%)$ & $\mathrm{CaO}(\mathrm{wt} \%)$ & $\mathrm{SiO}_{2}(\mathrm{wt} \%)$ & $\mathrm{R}\left(\mathrm{CaO} / \mathrm{SiO}_{2}\right)$ \\
\hline L-1.3 & 58.64 & 1.30 & 7.11 & 5.23 & 1.36 \\
L-1.7 & 57.42 & 1.70 & 6.92 & 5.09 & 1.36 \\
L-2.1 & 56.99 & 2.10 & 6.91 & 5.08 & 1.36 \\
L-2.5 & 56.63 & 2.50 & 6.88 & 5.06 & 1.36 \\
L-3.0 & 56.49 & 3.00 & 6.80 & 5.00 & 1.36 \\
H-1.3 & 55.62 & 1.30 & 9.19 & 5.22 & 1.76 \\
H-1.7 & 55.25 & 1.70 & 9.06 & 5.15 & 1.76 \\
H-2.1 & 55.02 & 2.10 & 9.06 & 5.15 & 1.76 \\
H-2.5 & 54.81 & 2.50 & 9.03 & 5.13 & 1.76 \\
H-3.0 & 54.51 & 3.00 & 8.89 & 5.05 & 1.76 \\
\hline & & & & &
\end{tabular}

Table 2. Experimental condition of sintering test.

\begin{tabular}{cc}
\hline Bed height: $500 \mathrm{~mm}$ & Sintering pot diameter: $150 \mathrm{~mm}$ \\
Ignition pressure: $4.9 \mathrm{kPa}$ & Exhausting pressure: $9.8 \mathrm{kPa}$ \\
Ignition temperature: $1000^{\circ} \mathrm{C}$ & Ignition time: $1.5 \mathrm{~min}$ \\
Carbon content in blend: $4 \%$ & Water content in blend: $(8.0 \pm 0.5) \%$ \\
Return fines content: $30 \%$ & Height of grate layer: $20 \mathrm{~mm}$ \\
Basicity $\left(\mathrm{R}=\mathrm{CaO} / \mathrm{SiO}_{2}\right): 1.36$ or 1.76 & Pelletizing time: $10 \mathrm{~min}$ \\
\hline
\end{tabular}

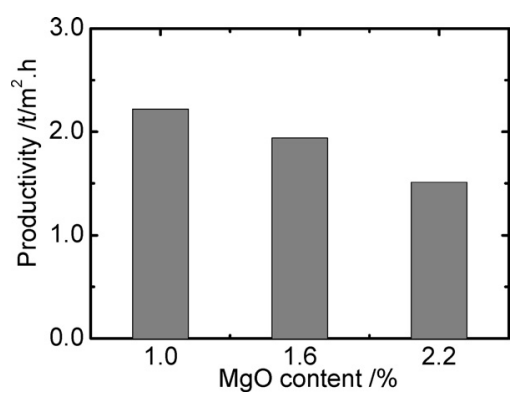

Fig. 1. Effect of $\mathrm{MgO}$ content on productivity of sintering.

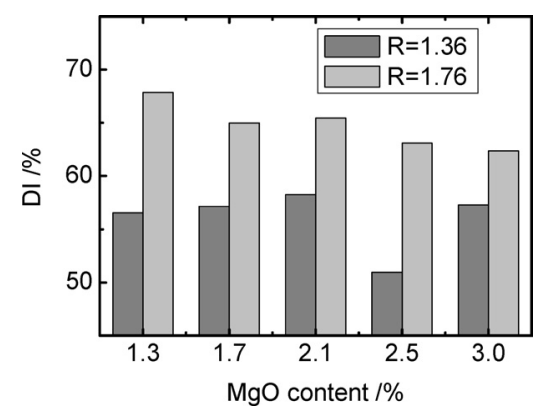

Fig. 2. Effect of $\mathrm{MgO}$ content on drum index of sinter. and pelletization performance.

To sum up above, the addition of dolomite i.e. (MgO) will have negative effect on sintering process.

\section{Effect of MgO on Softening/Melting Behaviour of Sintered Ore}

\subsection{Experiment}

A $\Phi 75 \mathrm{~mm}$ (inner diameter) graphite crucible, with a $\Phi 10 \mathrm{~mm}$ dripping hole on the bottom, is used in the experiment. $500 \mathrm{~g}$ sintered ore sample (size: $10-12.5 \mathrm{~mm}$ ) is charged into graphite crucible to $65 \mathrm{~mm}$ high. Coke is laid under the bottom and on the top of sample column to ensure molten materials and gas flow can pass through bed easily. The details of this experimental apparatus and condition can be found in reference. ${ }^{10)}$ In order to simulate the heating up and reduction process of sinter in BF, the experimental conditions are determined as Table 3. After experiment, the dripping slag and residual slag in crucible are taken out for further analysis.

The temperature when shrinkage ratio comes to $10 \%$ is defined as the upper temperature $\left(T_{10}\right)$ of cohesive zone and likewise the temperature when dripping starts is defined as the bottom temperature $\left(T_{\mathrm{D}}\right)$ of cohesive zone, and then the temperature range of cohesive zone $(\Delta T)$ is defined as

$$
\Delta T=T_{\mathrm{D}}-T_{10}
$$

The maximum resistance of material bed to gas flow during softening/melting process is defined as the maximum pressure drop $\left(\Delta P_{\max }\right)$.

\subsection{Results and Discussion}

Figure 3 shows the effect of $\mathrm{MgO}$ content on upper temperature $\left(T_{10}\right)$, temperature range of cohesive zone $(\Delta T)$ and maximum pressure drop $\left(\Delta P_{\max }\right)$. When $\mathrm{MgO}$ content increases from 1.3 to $3.0 \%, T_{10}$ has a small fluctuation (Fig. 3(a)), while $\Delta T$ has a great increase (Fig. 3(b)) and as a result, $\Delta P_{\max }$ has a significant increase (Fig. 3(c)). Under lower basicity $(R=1.36), \mathrm{MgO}$ content has a great effect on thickness of cohesive zone, but the absolute value of temperature range of cohesive zone with $3.0 \% \mathrm{MgO}$ addition is still low, only $325.5^{\circ} \mathrm{C}$. Under higher basicity $(R=1.76)$, the temperature range of cohesive zone is increased form 310.5 to $389.3^{\circ} \mathrm{C}$. Therefore, under the same operational condition, the temperature range of cohesive zone is much wider when using sintered ore of high basicity with high $\mathrm{MgO}$ content than using self-fluxing sintered ore with high $\mathrm{MgO}$.

In order to clarify the effect of $\mathrm{MgO}$ on softening/melt-

Table 3. Experimental conditions for softening/melting examination of sintered ore.

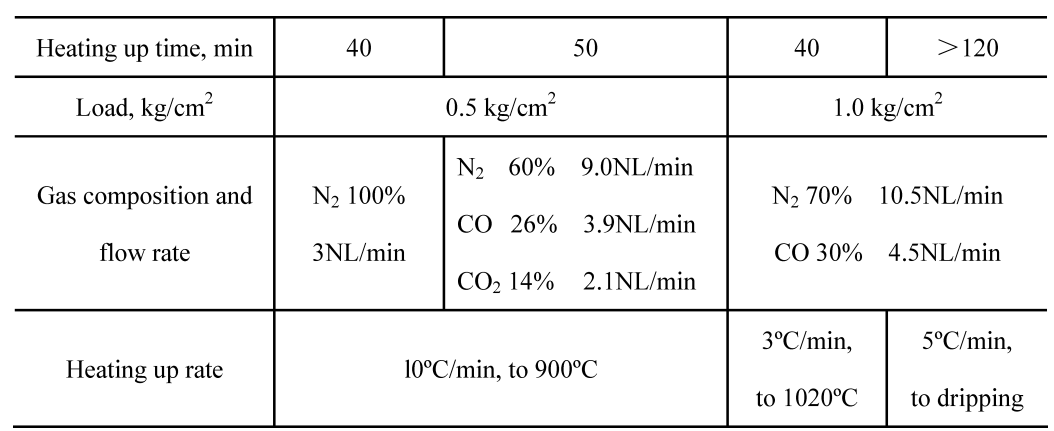




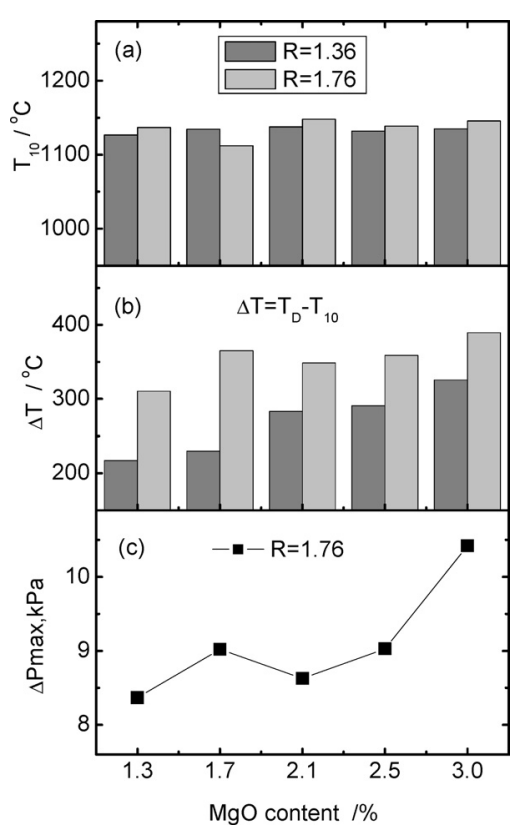

Fig. 3. Effect of $\mathrm{MgO}$ content on $T_{10}, \Delta T$ and $\Delta P_{\max }$.

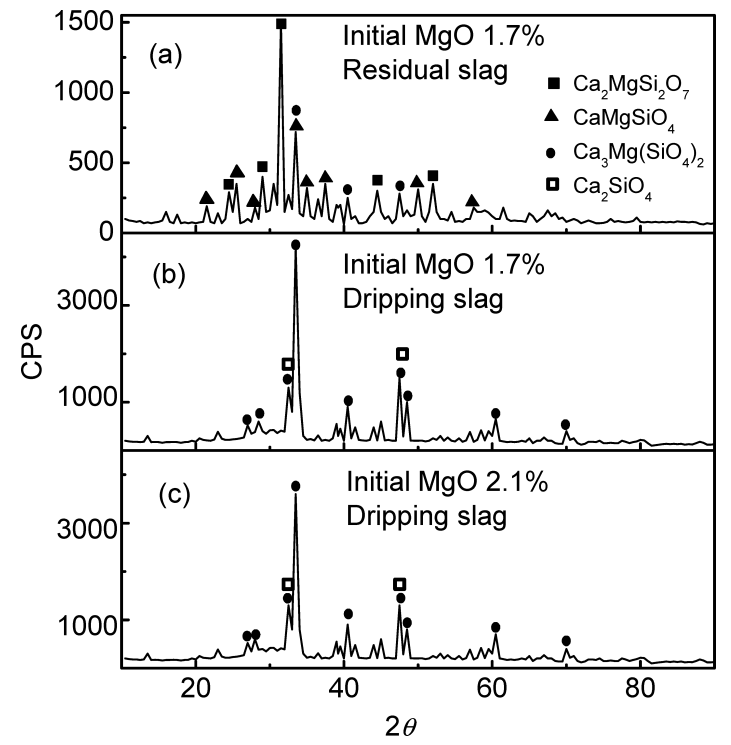

Fig. 4. X-ray diffraction of dripping slag and residuals slag.

ing behavior, X-ray diffraction is used to analyse the dripping slag and residual slag of sintered ore with various $\mathrm{MgO}$ contents (Fig. 4).

The results of X-ray diffraction show that: the main components of dripping slag are merwinite $\left[\mathrm{Ca}_{3} \mathrm{Mg}\left(\mathrm{SiO}_{4}\right)_{2}\right]$ and larnite $\left[\mathrm{Ca}_{2} \mathrm{SiO}_{4}\right]$, and those of residual slag are akermnite $\left[\mathrm{Ca}_{2} \mathrm{MgSi}_{2} \mathrm{O}_{7}\right]$, merwinite $\left[\mathrm{Ca}_{3} \mathrm{Mg}\left(\mathrm{SiO}_{4}\right)_{2}\right]$ and monticellite $\left[\mathrm{CaMgSiO}_{4}\right]$. The chemical composition of slag is listed in Table 4. It shows that, (a) the $\mathrm{MgO}$ content in dripping slag has no relation with the initial $\mathrm{MgO}$ addition, (b) the $\mathrm{MgO}$ content in dripping slag is double of that in residual slag. It can be deduced that, the slag containing high $\mathrm{MgO}$ cannot come to dripping easily and therefore the temperature range of cohesive zone will be increased much, and then the permeability of BF burden will be worse and this is not favorable for BF operation.
Table 4. Chemical composition of dripping and residual slags of sintered ore $(\mathrm{wt} \%)$.

\begin{tabular}{cccccc}
\hline Sample & Initial MgO content & $\mathrm{TFe}$ & $\mathrm{MgO}$ & $\mathrm{CaO}$ & $\mathrm{SiO}_{2}$ \\
\hline Residual slag & 1.7 & 2.77 & 11.45 & 36.71 & 33.55 \\
Dripping slag & 1.7 & 1.64 & 6.94 & 39.35 & 35.74 \\
Dripping slag & 2.1 & 1.66 & 5.99 & 39.72 & 35.89 \\
\hline
\end{tabular}

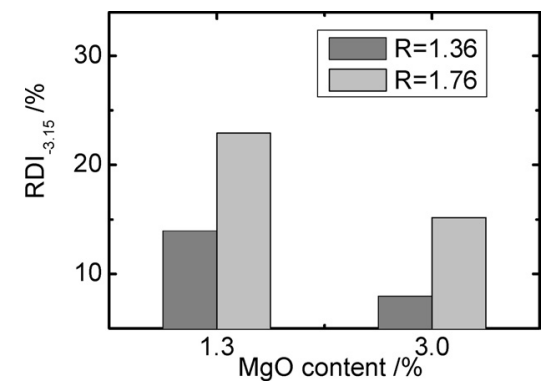

Fig. 5. Relationship between $\mathrm{MgO}$ content and $\mathrm{RDI}{ }_{-3.15}$.

\section{Effect of MgO on RDI of Sintered Ore}

Under laboratory condition, the effect of $\mathrm{MgO}$ on RDI of sintered ore is examined according to ISO standard.

\subsection{Results and Discussion}

Figure 5 shows the effect of $\mathrm{MgO}$ on RDI. It shows that as $\mathrm{MgO}$ content increases $\mathrm{RDI}_{-3.15}$ is decreased significantly. That is to say, increasing $\mathrm{MgO}$ content is favourable to decrease the RDI.

Concerning the mechanism of $\mathrm{MgO}$ can decrease RDI of sintered ore, according to EPMA analysis for test H-2.5, Fig. 6(c) shows the $\mathrm{MgO}$ distribution inside sintered ore with dolomite $\left(\mathrm{CaCO}_{3} \cdot \mathrm{MgCO}_{3}\right)$ addition. It shows that most of $\mathrm{MgO}$ particles will react with ferrous oxide and form solid solution, and then are dispersed in sintered ore. Therefore it can be deduced that, under high roasting temperature, the $\mathrm{MgO}$ particles diffused into ferrous oxide can prevent both the secondary $\mathrm{Fe}_{2} \mathrm{O}_{3}$ formation when sintered ore is cooling down ${ }^{11)}$ and the low temperature reduction of ferrous oxide inside the sintered ore. Therefore the RDI of sintered ore can be decreased by $\mathrm{MgO}$ addition.

\subsection{Counter-measure for Reduction Disintegration of Sintered ore under Low Temperature}

As discussed above, no or less $\mathrm{MgO}$ addition in sintering process can increase its productivity and improve cold strength and high temperature metallurgical properties of sintered ore. However, if $\mathrm{MgO}$ content in sintered ore is too low, the sintered ore will be disintegrated easily when reduced at low temperature. In order to solve this problem, the solution is proposed that $\mathrm{CaCl}_{2}$ solution is sprayed on the surface of sintered ore based on previous study. ${ }^{12,13)}$

Studies show that, the mechanism that $\mathrm{CaCl}_{2}$ can decrease RDI of sintered ore is, $\mathrm{CaCl}_{2}$ solution sprayed on surface of sintered ore will be absorbed and form a thin film on the surface of sintered ore. This film can then prevent the contact between reducing gas and surface of sintered ore and stop reducing gas from entering the sintered ore, and therefore the film can stop the potential reduction 


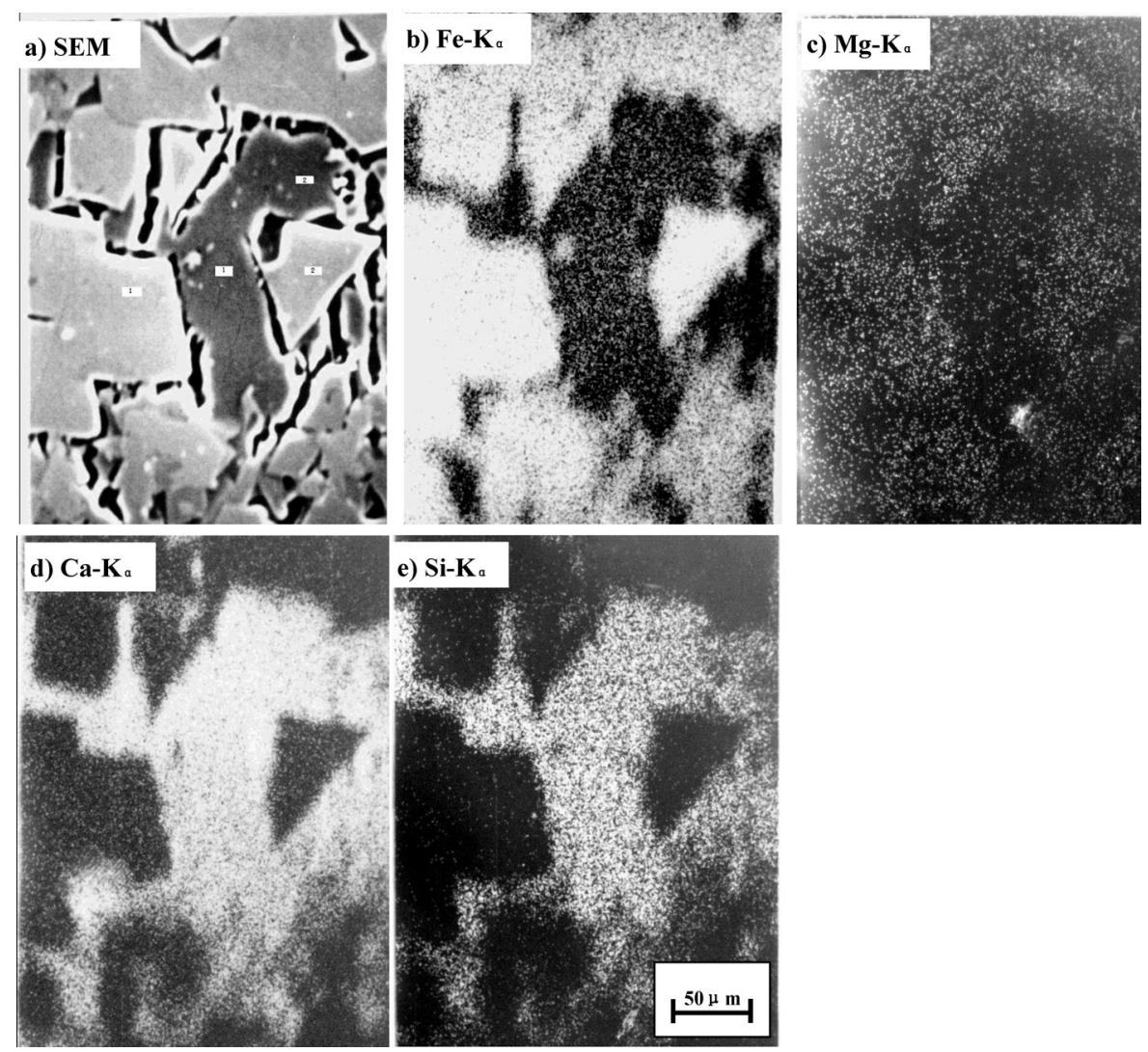

Fig. 6. Distribution of main elements (Fe, $\mathrm{Mg}, \mathrm{Ca}, \mathrm{Si})$ inside sintered ore (H-2.5).

reaction inside the ore. As a result, the reduction rate will be lowered and the RDI can be decreased.

\section{Proposal of New Process of Proper MgO Addition into $\mathbf{B F}$}

To ensure the BF slag contains certain amount of $\mathrm{MgO}$, in the conventional industrial operation, dolomite or magnesite is added into raw materials for sintering and then the sintered ore will be charged into BF from the top. These processes have the advantages of 1) maintaining $\mathrm{MgO}$ content in slag; 2) low RDI of sintered ore etc. However, they have also disadvantages: 1) low productivity of sintering; 2) bad cold strength of sintered ore; 3 ) leading to big temperature range of cohesive zone and big cohesive zone thickness, which will then make total pressure drop of BF increase much. Therefore, in order to ensure proper $\mathrm{MgO}$ content in BF slag and avoid the disadvantages of $\mathrm{MgO}$ addition during sintering, it is necessary to propose a new process of appropriate $\mathrm{MgO}$ addition into $\mathrm{BF}$.

From above results and discussion, a new process of proper $\mathrm{MgO}$ addition into $\mathrm{BF}$ is proposed: 1) adding no or less $\mathrm{MgO}$ into raw materials of sintering; 2) spraying $\mathrm{CaCl}_{2}$ solution on surface of sintered ore to control RDI of sintered ore; 3 ) instead of adding $\mathrm{MgO}$ in sintering in the conventional process, the required amount of $\mathrm{MgO}$ is added into $\mathrm{BF}$ by injection through tuyere together with $\mathrm{PC}$. The features of this new process are as follows: 1) $\mathrm{MgO}$ adding method is modified: all or part of $\mathrm{MgO}$ is injected into $\mathrm{BF}$ through tuyere together with $\mathrm{PC}$, instead of adding all of them during sintering. Thus sintered ore with no or low content of $\mathrm{MgO}$ will be produced and as a result the pro- ductivity of sintering will be improved, and product yield and cold strength of sintered ore will be increased, which will greatly improve high temperature softening/melting performance of sintered ore, compared with high $\mathrm{MgO}$ (especially high basicity) sintered ore. Then the thickness of cohesive zone in BF can be decreased and the total pressure drop will be decreased. 2) Raw coal and additive containing $\mathrm{MgO}$ are pulverized together by coal grinding mill, then PC containing $\mathrm{MgO}$ will be injected into $\mathrm{BF}$ through tuyeres, to ensure slag containing required content of $\mathrm{MgO}$, improve slag fluidity and desulphurization performance, and increase PC combustion at the same time. ${ }^{14)} 3$ ) Due to adding no or low $\mathrm{MgO}$ into sintering, RDI of sintered ore will be deteriorated. This problem can be solved by spraying $\mathrm{CaCl}_{2}$ solution on surface of sintered ore.

\section{Conclusions}

Based on experimental study and theoretical analysis, it can be concluded that

(1) Decreasing $\mathrm{MgO}$ addition in sintering can increase sintering productivity, cold strength of sintered ore, and decrease the temperature range of cohesive zone.

(2) RDI problem of low-MgO sintered ore can be solved by spraying $\mathrm{CaCl}_{2}$ solution on the surface of sintered ore.

(3) A new process for $\mathrm{MgO}$ addition is proposed. It has many advantages for both sintering process and BF operations, such as, 1) high productivity of sintering; 2) low RDI and high cold strength of sintered ore; 3 ) small temperature range of cohesive zone and better permeability in lumpy zone and cohesive zone; 4) higher PC combustion efficien- 
cy in raceway; 5) better slag fluidity and desulphurization performance.

\section{REFERENCES}

1) M. Matsumura, K. Snahara and M. Hoshi: CAMP-ISIJ, 17 (2004), 812 .

2) K. Higuchi, M. Naito, M. Nakano and Y. Takamoto: ISIJ Int., 44 (2004), 2057.

3) M. Nakano, M. Naito, K. Higuchi and K. Morimoto: ISIJ Int., 44 (2004), 2079.

4) H. Kimura and F. Tsukihashi: Proc. Int. Symp.: Science and Technology of Innovative Ironmaking for Aiming at Energy Half Consumption, MEXT, Tokyo, Japan, (2003), 83.

5) J. Lang, Z. Li and Y. Zhang: Multipurpose Utilization Miner. Resour., (2000), No. 1, 22.
6) Y. Zhang, X. Feng, Z. Li, J. Tian, G. Li, S. Gong, C. Zhang, Q. Qiao and H. Li: Sintering Pelletizing, 29 (2004), 4.

7) K. Kimura and F. Tsukihashi: CAMP-ISIJ, 17 (2004), 574

8) Y. Yamaoka, H. Horita, S. Kajikawa and K. Furukawa: Tetsu-toHagané, 67 (1981), S43.

9) Q. Zhou and L. Kong: Theory and Process of Agglomerate, The Chinese Society for Metal, Beijing, (1985), 8.

10) X. Jiang, G. Wu, G. Wei, and F. Shen: "The efects of MgO addition on softening and melting properties of sinter", submitted to Acta Metall. Sin.

11) S. C. Panigraphy, P. Verstraeten and J. Dilewijns: Metall. Trans. B, 15 (1984), 23.

12) N. Taguchi, T. Otomo and Y. Omori: ISIJ Int., 30 (1990), 281.

13) X. Wu: mater thesis, Northeastern University, (2003).

14) F. Shen, H. Du, X. Liu and C. Hou: J. Northeastern University, Natural Science, 17 (1996), 167. 